\title{
EDUCAÇÃO PERMANENTE: PROPOSTAS E DESAFIOS PARA OS ASSISTENTES SOCIAIS
}

\author{
Permanent Education: proposals and challenges for Social Workers
}

\author{
Nilsen Aparecida Vieira Marcondes ${ }^{1}$ \\ Elisa Maria Andrade Brisola ${ }^{2}$ \\ Edna Maria Querido de Oliveira Chamon ${ }^{3}$
}

\section{Resumo}

Neste artigo busca-se refletir sobre as propostas e desafios que se colocam quando o que se está em pauta é um repensar da educação permanente do assistente social. O estudo foi realizado por meio de uma pesquisa qualitativa, utilizando-se da história oral, através de entrevista semiestruturada. Partiu-se das narrativas dos entrevistados que atuam nos Centros de Referência da Assistência Social e nas Organizações Sociais de três municípios distintos, considerados de pequeno, médio e grande portes. Os resultados evidenciaram que, não obstante aos desafios, muitas são as possibilidades que podem contribuir para que novos horizontes sejam abertos na direção da educação permanente do profissional.

Palavras-chave: Educação Permanente. Assistente Social. Propostas. Desafios.

\begin{abstract}
This article seeks to reflect on the proposals and challenges faced when what is at issue is a rethinking of the education of the social worker. The study was conducted through a qualitative research, using oral history, through semi-structured interviews. Broke the narratives of respondents who work in the Reference Centres for Social Assistance and Social Organizations in three different towns, considered small, medium and large. The results showed that, despite the challenges, there are many possibilities that can contribute to new horizons are opened toward the continuing education of professionals.
\end{abstract}

Keywords: Continuous Education. Social Worker. Propositions. Defies.

\footnotetext{
${ }^{1}$ Assistente Social, Mestre em Desenvolvimento Humano - Formação, Políticas e Práticas Sociais pela Universidade de Taubaté. E-mail: nilsenmarcondes@gmail.com.

${ }^{2}$ Assistente Social, Doutora em Serviço Social pela Pontifícia Universidade Católica de São Paulo é Docente no Departamento de Serviço Social e no Programa de Pós-Graduação Stricto Sensu em Educação e Desenvolvimento Humano da Universidade de Taubaté. E-mail: elisabrisola@uol.com.br.

${ }^{3}$ Coordenadora do Programa de Pós-Graduação Stricto Sensu em Educação e Desenvolvimento Humano da Universidade de Taubaté. E-mail: edna.chamon@gmail.com.

Serv. Soc. \& Saúde, Campinas, SP v. 13, n. 2 (18) p. 299-322 jul./dez. 2014 ISSN 1676-6806
} 


\section{INTRODUÇÃO}

À luz dos elementos conceituais e dos dispositivos normativos que consubstanciam o Sistema Único da Assistência Social (SUAS), refletir sobre as propostas e desafios que se colocam à educação permanente do assistente social, apresenta-se como importante realidade afeta à atualidade interventiva dos profissionais de Serviço Social.

No cenário sócio histórico atual situam-se dois documentos que demarcam de maneira inconteste a relevância da centralização do debate em torno da educação permanente enquanto práxis: Norma Operacional Básica de Recursos Humanos do Sistema Único da Assistência Social (NOB-RH/SUAS) e Política de Educação Permanente voltada aos assistentes sociais.

A NOB-RH/SUAS caracteriza-se como um importante eixo reflexivo ao lado da evidente tematização da educação permanente, sendo considerada como Política de Recursos Humanos no âmbito do SUAS. A Política Nacional de Assistência Social (PNAS) implantada em 2004 já apontava para a necessidade de construção da NOBRH/SUAS. Este instrumento normativo foi aprovado por meio da Resolução ${ }^{\circ}$ 269, de 13 de dezembro de 2006, do Conselho Nacional de Assistência Social (CNAS), e, em 25 de janeiro de 2007, seu texto foi publicado através da Resolução nº 1 deste CNAS.

$\mathrm{Na}$ NOB-RH/SUAS, merecem destaque algumas considerações. A primeira delas se refere ao fato de que a viabilização dos serviços socioassistenciais ocorre mediante atuação de um conjunto de trabalhadores da Política de Assistência Social. É por intermédio desses profissionais que se conduzem e se ofertam os serviços. Uma segunda consideração importante se refere à ressignificação nominal que tais profissionais receberam, porque anteriormente ao SUAS eram comumente denominados viabilizadores de programas e atualmente passam a ser considerados viabilizadores de direitos, porque a concepção da assistência social como direito impõe este entendimento e isso muda substancialmente o processo de trabalho (BRASIL, 2004).

O Código de Ética do Assistente Social, em consonância com a NOBRH/SUAS, cita em seu artigo $2^{\circ}$, inciso $f$, dentre outros direitos, o seguinte: "constituem direito do assistente social: aprimoramento profissional de forma contínua" (CONSELHO REGIONAL DE SERVIÇO SOCIAL, 2007, p. 20).

Em relação à Política de Educação Permanente, tornada pública à categoria profissional em setembro de 2012, embora esteja ainda em construção, verifica-se Serv. Soc. \& Saúde, Campinas, SP v. 13, n. 2 (18) p. 299-322 jul./dez. 2014 ISSN 1676-6806 
tratar de "um instrumento político a fortalecer a formação e o exercício profissional e contribuir para a garantia da qualidade dos serviços prestados à população usuária do Serviço Social brasileiro", sendo que sua materialização exige “coragem, organização, capacidade crítica e unidade" por parte dos assistentes sociais (CONSELHO FEDERAL DE SERVIÇO SOCIAL, 2012, p. 2).

A Política de Educação Permanente foi elaborada pelo Conselho Federal de Serviço Social (CFESS) em conjunto com os Conselhos Regionais de Serviço Social (CRESS) e valendo-se da sua dimensão política e pedagógica, tem como objetivo a consolidação de uma Política Nacional de Educação Permanente em que fique evidenciada a relevância do aperfeiçoamento intelectual, técnico e político dos profissionais de Serviço Social. Essa política revela seus méritos também, enquanto conquista para a categoria profissional, na medida em que é considerada como materialização de um estudo nacional voltado ao debate sobre qualificação continuada e reafirmação "das conquistas já galgadas na profissão, que tem na produção e socialização de conhecimentos um dos pilares das ações de formação" (CONSELHO FEDERAL DE SERVIÇO SOCIAL, 2012, p. 9-10).

O texto da Política de Educação Permanente considera ainda a diferenciação entre formação continuada e educação permanente. Ambas se configuram como realidades temporais que expressam continuidade de aprendizagem durante todo o decorrer da vida profissional e pessoal, entretanto, estão imersas em princípios metodológicos distintos. A formação continuada diz respeito à continuidade da formação acadêmica inicial, com vistas ao aperfeiçoamento profissional. Porém, não se considera como regra que tal aperfeiçoamento se volte para as necessidades decorrentes do espaço sócio ocupacional ou na direção de alterações qualitativas nas estruturas e nas rotinas e fluxos de atendimento das demandas emergentes. Sob outra ótica, encontra-se a acepção de educação permanente. Esta deve ser entendida no cenário histórico, político e econômico, atentando-se para as metamorfoses que ocorrem na sociedade e as necessidades emergentes dos que procuram pela Assistência Social, considerando que todos esses aspectos influenciam a área da educação, a formação profissional e a própria intervenção cotidiana (CONSELHO FEDERAL DE SERVIÇO SOCIAL, 2012).

Sabe-se que a construção histórica da profissão de todos os trabalhadores do SUAS foi profundamente marcada por estigmas decorrentes da não exigência de racionalidade técnica e não necessidade de uma base de sustentação científicoServ. Soc. \& Saúde, Campinas, SP v. 13, n. 2 (18) p. 299-322 jul./dez. 2014 ISSN 1676-6806 
metodológica capaz e adequada para garantir o desenvolvimento contínuo dos assistentes sociais. Com isso, os resultados das ações executadas também apresentavam menor qualidade do que o esperado e desejado pelos profissionais e pelos destinatários destas ações (CONSELHO FEDERAL DE SERVIÇO SOCIAL, 2009).

Por conseguinte, é justamente o destaque da importância da educação permanente, materializada em propostas e desafios, que ganha centralidade nas análises e reflexões deste artigo. Entende-se que se tal continuidade da formação for desconsiderada, as ações realizadas serão provavelmente reproduzidas durante o processo de construção do novo cenário histórico que se pretende substitutivo para a profissão, contrário ao anterior estigmatizado. Para tanto, é desejável que o assistente social busque dar materialidade e concretude às dimensões teórico-metodológica, técnico-operativa, investigativa e formativa, alicerçadas na dimensão ético-política da profissão.

Segundo Nogueira (2005), a dimensão teórico-metodológica diz respeito à forma de ler e interpretar toda a realidade de natureza exógena e endógena da profissão, embora, na maioria das vezes, essas realidades se constituam como fenômenos que evidenciam a necessidade de reconstrução das demandas e possibilidades interventivas do Serviço Social, mediadas pelas determinações sócio-históricas e pelos projetos hegemônicos da sociedade.

Para Guerra (2005), a dimensão teórico-metodológica se caracteriza como a capacidade de diferenciar os diversos conhecimentos existentes e suas aplicações no interior da profissão, levando o assistente social ao exercício de reflexão sobre a função da teoria para a execução da ação, possibilitando legitimar o que já existe ou emitir apreciação desfavorável, e ainda indicar alternativas de intervenção dentro de um determinado contexto.

Em relação à dimensão técnico-operativa, Guerra (2005) afirma se tratar das competências instrumentais que buscam capacitar o profissional para executar ações dentro dos mais diversos programas nos quais esteja inserido, realizar atendimentos pertinentes as suas demandas com competência, prover respostas tanto às necessidades imediatas quanto às mediatas e responsabilizar-se pelos seus compromissos. Nessa dimensão situam-se ainda: planejamento; formulação; administração e avaliação de políticas sociais; tomada de decisões; estabelecimento de prioridades; negociação e pactuação de estratégias; escolha de alternativas; elaboração de pareceres e laudos; Serv. Soc. \& Saúde, Campinas, SP v. 13, n. 2 (18) p. 299-322 jul./dez. 2014 ISSN 1676-6806 
realização de levantamentos socioeconômicos; emissão de respostas às demandas tradicionais, quais sejam, as de mobilização e organização social e às demandas atuais, como a avaliação das realidades sociais, o treinamento e desenvolvimento de recursos humanos, o cooperativismo, a gestão e controle social; assessoria aos conselhos de direitos que compõem no cenário das políticas públicas, aos movimentos sociais e aos sindicatos.

Quanto à dimensão investigativa, Guerra (2005) esclarece que esta envolve o encorajamento e a procura pela consolidação de um comportamento investigativo por parte do profissional, levando-o ao exercício da pesquisa, da reflexão sobre conjunturas e cenários sócio-históricos e institucionais, da formulação de diagnósticos, da procura por dados e conhecimentos sobre realidades, situações e sobre os destinatários dos serviços socioassistenciais. Esta dimensão possibilita também que o profissional possa lançar questionamentos sobre o cenário sócio-institucional e sobre as expressões sóciohistóricas do agir profissional.

Diniz (2003), ao se referir à dimensão formativa, considera que os assistentes sociais, como sujeitos históricos, são marcados por uma cultura que os caracteriza como idealizadores de ideias e formadores de opinião. Guerra (2005) reforça essa conceituação, defendendo que todo e qualquer profissional de Serviço Social possui potencial para direcionar suas ações no âmbito da formação em dois planos distintos: o da formação de opinião e o da formação profissional.

Em relação à formação de opinião, Guerra (2005) defende que o ato de se voltar para a busca do consensual, do acordo ou da concordância de ideias, de opiniões e de estratégias, está presente na atuação cotidiana do assistente social. Dessa forma, o profissional acaba exercendo em maior ou menor intensidade certa influência na vida daqueles que se utilizam da prestação de seus serviços. São, portanto, formadores de opinião.

Quanto à formação profissional, Guerra (2005) evidencia que se trata também de uma responsabilidade legalmente atribuída, portanto, maior que o compromisso com a dimensão profissional apenas. Nesse aspecto, situa-se, por exemplo, a intervenção voltada ao treinamento, avaliação e supervisão direta de alunos de Serviço Social que cumprem uma carga horária quando exercem a função de estagiários. É muito importante reconhecer que essa dimensão referente ao ensino de Serviço Social deve voltar-se para a formação profissional dos alunos que se encontram na graduação, mas Serv. Soc. \& Saúde, Campinas, SP v. 13, n. 2 (18) p. 299-322 jul./dez. 2014 ISSN 1676-6806 
também para a qualificação continuada dos assistentes sociais que desenvolvem suas ações nos mais diversos espaços sócio-ocupacionais.

Para Nogueira (2005, p. 188), a dimensãoético política relaciona-se aos "aspectos valorativos que orientam a ação profissional e que se expressam em dois vetores - o protagonismo dos usuários que passam a ser vistos como sujeitos políticos e a ideia da direção social e hegemonia." Essa dimensão, assim como as anteriores, é referendada no Código de Ética atual do assistente social.

Guerra (2005) reforça que a dimensão ético política direciona sua preocupação às necessidades coletivas e aos princípios que se configuram como alicerces da prática profissional. O interesse se volta também para a demonstração da relevância da definição dos elementos estratégicos, das ações pautadas por norteadores políticos interventivos e valores éticos que devem se fazer presentes nesse cenário interventivo. As políticas públicas, nessa dimensão, devem ser apreendidas como importantes mediadoras, pois evidenciam movimentos de avanços e recuos presentes no interior da sociedade, além de demonstrarem a correlação de forças das classes sociais, e apontar quais estratégias e táticas políticas estão sendo tomadas em determinado momento histórico.

Por fim, após breve percurso introdutório da NOB-RH/SUAS e da Política de Educação Permanente, bem como sintética reflexão ontológica sobre as diversas dimensões que compõem a profissão do assistente social, têm-se, na sequência, a apresentação da metodologia, dos resultados e discussão e por fim as considerações finais.

\section{Metodologia}

Para respaldar esta construção teórica, foi realizada uma pesquisa qualitativa, utilizando-se da história oral, através de entrevista semiestruturada. Os sujeitos deste estudo foram seis assistentes sociais assim distribuídos: um de um município de pequeno porte e atuante em unidade pública estatal, qual seja, o Centro de Referência de Assistência Social (CRAS) da cidade; um de um município de médio porte, exercendo suas atividades em organização social do segmento Pessoa com Deficiência e quatro de um município de grande porte, sendo dois profissionais representantes de dois CRAS da cidade e dois de organizações sociais, respectivamente, do segmento Família e Criança e Adolescente.

Serv. Soc. \& Saúde, Campinas, SP v. 13, n. 2 (18) p. 299-322 jul./dez. 2014 ISSN 1676-6806 
Os entrevistados participantes desta pesquisa consentiram com a realização do estudo, os quais tiveram esclarecimentos sobre os objetivos e assinaram o Termo de Consentimento Livre e Esclarecido. A pesquisa foi encaminhada ao Comitê de Ética da Universidade localizada na área de abrangência dos municípios pesquisados, tendo sido aprovada sob o Protocolo n. 379/11.

A primeira parte da coleta das informações consistiu no preenchimento de questões referentes à identificação do participante: nome, ano em que terminou o curso de Serviço Social, tempo de atuação como assistente social, cursos realizados após a graduação, local e cidade onde trabalha, e segmento em que atua (se família, criança e adolescente, idoso, pessoas com deficiência, etc.). A segunda parte da coleta ocorreu por meio da entrevista semiestruturada durante os meses de agosto e setembro de 2011, as quais foram gravadas em áudio e, posteriormente, transcritas. Nesta etapa da coleta de dados empíricos, os profissionais foram orientados sobre os eixos estruturadores da entrevista, a saber: propostas e desafios que se colocam quando o que se está em pauta é um repensar da educação permanente do assistente social.

Neste estudo, em especial, utilizou-se da História Oral na sua modalidade Narrativa. A História Oral requer a utilização de métodos e técnicas para a coleta das fontes orais, sendo que o recolhimento das informações se dá por meio de entrevistas. Por isso, para sustentação deste estudo optou-se pela utilização da entrevista semiestruturada.

Defende-se e se reconhece que as fontes orais, muitas vezes, são as únicas formas de registro e estudo de realidades tão específicas e particulares como o caso da percepção dos desafios, bem como indicativos de propostas que os assistentes sociais têm para a educação permanente. Como se sabe, muitos documentos não passam de transmissões de relatos orais. Essa certeza imprime credibilidade à fonte oral, tão importante quanto os registros escritos.

A característica elástica e flexível da História Oral permitiu trazer à tona dados relevantes do cotidiano prático dos assistentes sociais, que, talvez, por outra fonte não se conseguisse. Foi possível, ainda, colocar em evidência a fala apresentada sob a ótica das profissionais de Serviço Social, tornando-os atores da construção teórica presente neste estudo. Com a História Oral, chegou-se, por fim, ao conhecimento de uma historicidade local singular, visto que os pesquisados ocupavam historicamente um tempo e um espaço. Essa realidade veio ao encontro do que é defendido na NOB-RH/SUAS de que 
a educação permanente, no contexto do Sistema Único da Assistência Social, deve se pautar pelo respeito a diversidades e particularidades regionais e locais na elaboração dos planos de capacitação, mas sem deixar de considerar a uniformidade de conteúdo, carga horária e adequação aos diversos públicos (BRASIL, 2007).

A melhor forma de descobrir o que é importante e necessário para aquele sujeito individual, ou coletivo, daquele determinado local, com aquelas características singulares, é justamente perguntar-lhe diretamente quais suas necessidades, seus anseios, motivações, desejos de crescimento pessoal e profissional. Neste aspecto, a História Oral "caiu como uma luva" para o alcance desses objetivos, consciente de que ao se apoiar em narrativas orais, pode-se produzir conhecimentos. É importante frisar que, durante toda a fase da investigação, a reflexão e a análise se fizeram presentes, porque na História Oral a dialética faz parte do processo.

A História Oral enfatiza a importância de se partir do local em que o entrevistado ocupa no grupo e do significado de sua experiência, além de defender que as pessoas que participaram, vivenciaram, presenciaram fatos ou situações ligadas ao assunto em estudo, podem fornecer depoimentos e informações relevantes, importantes, significativas para a questão (ALBERTI, 2004).

Portanto, cada narrativa, recolhida e organizada, traz consigo a maneira pela qual o assistente social se expressa quando o assunto se refere às propostas e desafios que se colocam à educação permanente. Neste sentido buscar-se-á através do enfoque analítico da objetividade e da subjetividade, refletir sobre temas que permitem ampliar a compreensão de tais propostas e desafios que se apresentam aos assistentes sociais inseridos nas unidades estatais e organizações sociais.

\section{Resultados e Discussão}

A realidade social encontra-se em contínuo desenvolvimento, uma construção inacabada, por conseguinte, sujeita à mediação do tempo e do espaço, onde todo o conhecimento existente em seu interior é considerado como perpétuo até que seja substituído por um novo conhecimento. A vida em sociedade move-se no interior de um processo extremamente dinâmico. Uma característica marcante dessa ambiência societária é sua natureza social que se difere da natureza física e de suas variáveis explicativas e interpretativas, submetida, portanto a inúmeras realidades delimitadas 
pelo híbrido contexto dos processos relacionais societários e multiculturais (SPOSATI, 2007).

Essa constatação, portanto, revela a importância de se pensar continuamente nas propostas que melhor possam direcionar as ações que envolvem a educação permanente. Paralelamente, enquanto não se efetivam tais propostas, considera-se que as mesmas se encontram no patamar dos desafios a serem superados. É interessante, ainda, verificar que a realidade da educação permanente ultrapassa os muros do Serviço Social, configurando-se como questão de âmbito maior dentro da sociedade, conforme afirmam Gatti e Barretto (2009):

O interesse pelo tema da formação continuada difundiu-se nos últimos anos, envolvendo pesquisadores, acadêmicos, educadores e associações profissionais. Há uma grande mobilização em torno do assunto, a produção teórica é crescente, eventos oficiais e não oficiais propiciam debates e razoável circulação de análises e propostas. Observa-se que a formação continuada tem recebido atenção de destaque (GATTI; BARRETTO, 2009, p. 199).

Apesar de a discussão ser contínua e apresentar processo evolutivo considerável, essa tendência não é acompanhada por uma conceituação unívoca do termo, o que é saudável, porque as demandas por educação permanente variam conforme as necessidades profissionais individuais e coletivas, bem como o contexto e tipo de ação realizada. Além disso, a característica ontológica de expressões que designam a qualificação continuada também apresenta nuances distintas, conforme expressam as autoras Gatti e Barretto (2009):

A designação de formação continuada cobre um universo bastante heterogêneo de atividades, cuja natureza varia, desde formas mais institucionalizadas, que outorgam certificados com duração prevista e organização formal, até iniciativas menos formais que têm o propósito de contribuir para o desenvolvimento profissional, ocupando ou não as horas de trabalho, ou se efetivando como trocas entre pares, grupos de estudo e reflexão (Ibid., p. 200).

\section{Propostas}

Embora o cenário da educação permanente apresente similitudes em todo o território nacional, não se pode ignorar que em termos de propostas, deve-se considerar a realidade de cada espaço sócio ocupacional e de cada município em particular porque a compreensão do contexto histórico em tempos do SUAS prevê atenção à territorialização e à regionalização. 
Para Iamamoto (2005), "os espaços ocupacionais e as respostas profissionais são tratados sob angulações e direcionamentos diferenciados" (ibid., p. 141). Assim sendo, as propostas para efetivação de um programa de educação permanente devem ser consoantes às diretivas profissionais e às necessidades da população usuária.

De forma dialética, os interesses pela educação permanente advindos dos profissionais e da demanda por qualidade na prestação dos serviços por parte da população usuária se entrelaçam. E ainda, de acordo com Nogueira (2005), "as demandas colocadas à profissão, tanto em relação à sua natureza como em relação ao espaço sócio ocupacional onde se concretizam, vêm sendo alteradas de forma radical" (NOGUEIRA, 2005, p. 185).

Portanto, evidencia-se e legitima-se a importância de uma educação permanente que considere as inovações trazidas pelo SUAS em termos de estruturas de gestão da Política de Assistência Social, que, por sua vez, repercutem diretamente nas ações, responsabilidades e corresponsabilidades inerentes ao processo de implementação desse Sistema. Conforme defende Silveira (2009),

O SUAS, no âmbito local, possibilita a organização dos municípios por níveis de gestão com definição de responsabilidades, requisitos e incentivos na perspectiva do aprimoramento constante da capacidade em gerir a política de assistência social” (Ibid., p. 351).

O SUAS propõe maior estímulo à educação permanente com vistas à busca da qualidade dos serviços prestados. E este estímulo, desde que respaldado nas necessidades dos profissionais e na realidade local, se configura como importante contributo à efetivação da Política de Assistência Social, uma vez que o processo interventivo dos assistentes sociais que atuam nas políticas sociais pode contribuir na implantação e implementação do próprio SUAS. Segundo Silveira (2009), isso é possível de ser realizado mediante compreensão do dinamismo cotidiano e das possibilidades potencializadoras de transformação, bem como da tomada e aplicação de consistentes ferramentas político-pedagógicas.

Em se tratando de educação permanente, é importante também passar das necessidades básicas de aprimoramento para as necessidades sociais, coletivas da categoria. É justamente esse aspecto social da educação permanente que deve ser ampliado gradativamente. Com isso, não se quer dizer que as necessidades básicas e locais de qualificação profissional sejam menos importantes. Reforça-se que as necessidades básicas, as quais emergem do cotidiano do profissional localizado num 
determinado município, operacionalizando específicos programas e projetos e executando determinados serviços, são igualmente importantes e existem justamente para que se possa inseri-las nas necessidades coletivas de educação permanente por parte da categoria. O que se defende é que as respostas dos profissionais em termo de educação permanente às questões temporais que se apresentam no município são importantes. Entretanto, tem-se também consciência de que somente se consegue se fazer visível este ou aquele profissional quando o mesmo se torna sujeito coletivo.

A percepção daquilo que se almeja para a materialização do SUAS nos municípios precisa estar em sintonia com a realidade nacional da Política de Assistência Social, porque pensar coletivamente a educação permanente é uma necessidade. E é uma necessidade, porque este movimento reflexivo e coletivo permite identificar o universo de maior fragilidade ou maior demanda por educação permanente nos municípios. Essa inserção contínua na Política de Assistência Social precisa ocorrer sempre que se for pensar em qualificação profissional, independente do âmbito de ação estar situado no plano municipal, estadual ou federal.

O alinhamento dos interesses dos profissionais na direção da PNAS permite discutir com mais propriedade determinadas demandas por educação permanente, além de favorecer e incentivar a consolidação de parcerias na disponibilização de espaços para a qualificação profissional, o que é essencial. A ampliação do acesso às oportunidades de educação permanente pode ser protagonizada por vários atores, não necessariamente gestores municipais da assistência social, mas também gestores, estaduais, federais, órgãos representativos da categoria, universidades e pelos próprios assistentes sociais. Portanto, as iniciativas na direção da educação permanente podem e devem partir, num primeiro momento, do nível local, como preconiza o próprio SUAS.

Isso posto, e considerando as possibilidades e limites de cada protagonista potencialmente responsável pela oferta de espaços de educação permanente, as propostas dos profissionais entrevistados, a seguir, apontam para direções exequíveis:

Poderemos sugerir várias coisas, mas a que fica presente para mim seria que o gestor municipal pudesse propiciar a mesma condição de participação e aprimoramento na formação continuada aos técnicos das organizações sociais, da mesma forma que oferece aos técnicos diretamente ligados à Secretaria. Defendo a ideia de que todos os profissionais de Serviço Social estão envolvidos na construção da história da Política da Assistência no município, portanto todos deveriam ser protagonistas nas discussões para o enfrentamento da exclusão social. (E1) 
Nem sempre conseguimos discutir o conteúdo lido. Com certeza quando alguém nos fala sobre as nossas siglas, porque são muitas ou quando discutimos o assunto, fica muito mais fácil à compreensão do que apenas ler e tentar por si mesma entender. Um exemplo quanto à importância de discussão dos conteúdos estudados se refere aos benefícios previdenciários, pois tive a oportunidade de participar de uma capacitação oferecida pelo INSS [Instituto Nacional de Seguridade Social] de uma cidade de outro estado, estado do Paraná logo após implantação da Lei Orgânica da Assistência Social em 1995 e é isso que ainda me subsidia nos atendimentos que realizo atualmente quando me refiro a esse tema benefícios previdenciários. É claro que fui me inteirando de algumas e poucas alterações dentro deste período na Instituição onde trabalho. E ainda, não há investimento, por parte do gestor municipal, na aquisição de livros com assuntos pertinentes ao nosso trabalho, entretanto como acredito que sejam de extrema importância na medida em que respaldam e fortalecem nossa atuação, tenho adquirido com recursos próprios os títulos que mais diretamente dizem respeito ao meu trabalho. A aquisição continuada de livros por parte do órgão gestor permitiria criar e manter uma biblioteca atualizada em cada CRAS, e seria de grande valia, pois isso permitiria que os profissionais da rede pública e privada localizados ao redor do CRAS pudessem fazer consultas, possibilitando estudos e reflexões conjuntas fortalecendo e respaldando a nossa atuação. Também, como sou supervisora de estágio, há necessidade de buscar literatura para poder acompanhar o estagiário e lhe dar apoio quanto à elaboração do Trabalho de Conclusão de Curso, sendo também adquirida por iniciativa própria ou às vezes emprestada da própria biblioteca da Faculdade. Por fim, a supervisão técnica frequente seria de grande valia, assim como ocorre nas organizações sociais. (E5)

Sinto falta de grupos de estudos estruturados, onde se possam discutir as problemáticas da rotina dentro da Instituição. Em conversas com outros profissionais percebo que o desejo e as dificuldades são na maioria iguais ou parecidos. Então eu acho que isso viria contribuir muito não só para mim, mas como para os outros profissionais da rede. (E2)

Os conteúdos presentes nas narrativas dos assistentes sociais entrevistados fundamentam uma análise exploratória da realidade da educação permanente no contexto geral do SUAS, pois, conforme se observa em alguns documentos oficiais e nos textos de alguns autores, a questão deve ganhar centralidade nos tempos atuais, principalmente, após regulamentação da NOB-RH/SUAS (BRASIL, 2007, 2009, 2012; CARVALHO, 2006; FERNANDES, 2007; LOPES, 2006; MOTA et al., 2006; RAICHELIS, 2010; SILVEIRA, 2009; SPOSATI, 2006).

Outras evidências empíricas também tornadas candentes às autoras deste artigo, mediante participação das mesmas em espaços coletivos de educação permanente, promovidos pelas universidades, CRESS e prefeituras, somadas as que foram Serv. Soc. \& Saúde, Campinas, SP v. 13, n. 2 (18) p. 299-322 jul./dez. 2014 ISSN 1676-6806 
trabalhadas neste estudo, advindas das investigações realizadas nos três municípios com assistentes sociais das unidades estatais e organizações sociais, apontam na direção de que é inegável a importância da educação permanente como um dos contributos para romper com a tradição conservadora da assistência social.

Pode-se afirmar, portanto, que a qualificação continuada acentua os avanços que o SUAS veio trazer à Política de Assistência Social no que se refere à prioridade em normatizar a proteção social básica e especial por meio da instituição dos Centros de Referência de Assistência Social, Centros de Referência Especializado de Assistência Social (CREAS), reforçando os aspectos protetivo, preventivo, descentralizado, territorializado e a matricialidade sociofamiliar, realidades defendidas na nova gestão da Assistência Social.

A evolução da Assistência Social como política ocorreu mediante esforço de uma parcela considerável de sujeitos políticos organizados. Embora, hoje, seja preciso reconhecer que muito ainda há por fazer, não se pode desconsiderar a identidade positiva que, gradativamente, a Assistência Social vai assumindo nas três instâncias federativas, reforçando sua dimensão de dever do Estado e direito de cidadania. O protagonismo dos profissionais responsáveis pela implantação e implementação dessa política, é consolidado pela busca da educação permanente, capaz de imprimir uma importante e significativa qualidade na execução dos serviços socioassistenciais executados.

Outra questão não menos importante, mencionada nas narrativas, se refere ao fato de haver preponderância e incentivo à realização de ações fragmentadas e isoladas. É notório também verificar que despontam das reflexões dos entrevistados preocupações com as atribuições e competências realizadas isoladamente. Isso reforça o que Paiva (2006) chama de presença de resquícios de uma característica tradicional da Assistência Social quando aprisionada num cenário governamental que reproduzia mecanismos frequentes que burlavam as desigualdades e encobriam suas causas, restringindo suas soluções a programas pontuais, supostamente restauradores das posturas individuais e grupais, esvaziadas de conteúdo ou potencial transformador libertário.

Os assistentes sociais são claros ao afirmar que o desenvolvimento de ações isoladas culmina na consolidação de uma trajetória profissional que destoa daquela a que realmente se pretende construir. Como a execução dessas ações fragmentadas é Serv. Soc. \& Saúde, Campinas, SP v. 13, n. 2 (18) p. 299-322 jul./dez. 2014 ISSN 1676-6806 
sedimentada e naturalizada pelo sistema capitalista, uma das alternativas apresentada pelos entrevistados para seu enfrentamento se pauta na conquista e garantia de espaços que favoreçam os momentos de interação, reflexão e estudo coletivo de literaturas pertinentes, além da estruturação de acervos bibliográficos próximos aos espaços sócio ocupacionais, que permita consultas frequentes e a estruturação de grupos de estudo, bem como a supervisão técnica com vistas a garantir uma maior unicidade no plano interventivo.

Embora algumas dessas alternativas não garantam a leitura e o empenho do assistente social na direção de seu crescimento profissional, por outro lado, tais alternativas mostram-se capazes de referenciar e mesmo sustentar o interesse daqueles profissionais que, por iniciativa própria, buscam atualizar-se e reciclar-se com referências teóricas, críticas e atuais sobre a profissão, bem como inserir-se em espaços onde o estimulo à troca de conhecimentos e de experiências entre os profissionais seja uma constante.

Essas assertivas encontram ecos consentâneos com aquilo que é defendido por Fernandes (2007). Para essa autora, é necessário voltar-se para a construção de espaços compartilhados de reflexão crítica em torno da dinâmica de trabalho do profissional, ressaltando, ainda, que a educação permanente subentende aquisição de novos conhecimentos no próprio ambiente onde o assistente social realiza sua intervenção cotidiana, pois a partilha de saberes, a socialização recíproca do trabalho coletivo, por meio do respeito às diferenças, buscando a efetivação de mudanças, contribui para o alcance de novas aprendizagens.

Verifica-se que a valorização dos espaços coletivos de trabalho, como alternativa para desenvolvimento profissional, é recorrente nas falas dos entrevistados. Isso se dá porque esses profissionais se encontram diante da pouca oferta de oportunidades de formação continuada disponibilizada por parte do órgão gestor municipal, aliada à falta de incentivo para a realização desse investimento. Assim sendo, a garantia dos espaços para desenvolvimento de uma educação permanente se sobressai como alternativa no plano local, o que é muito importante, porque uma educação permanente não implica necessariamente a espera do incentivo ou da oferta, ao contrário, essa busca pode e deve também partir dos próprios profissionais.

Fernandes (2007, p. 215) ressalta que: 
Educação permanente é aprendizagem no próprio trabalho, é aprender com o outro, com as necessidades sociais. É compartilhar experiências e práticas, criando estratégias para agregar conhecimento no próprio ambiente de trabalho e propor mudanças. É saber conhecer e fazer. É descobrir e desvelar as potencialidades, fortalecendo a rede de serviços com os quais interagimos bem como consolidar o Projeto Ético-Político da profissão.

O SUAS enquanto um intento hegemônico que aponta para a universalização e para a equidade, num contexto dominado pelo capitalismo, e tendo em seu centro a desigualdade social se constitui como um paradoxo. Entretanto, é justamente este paradoxo que ensejará a formulação de uma política que visa à formação dos profissionais de Serviço Social em sintonia com a realidade histórica da atualidade. Portanto, o tripé - educação, trabalho e Serviço Social - consiste numa via a ser encorajada e direcionada por meio da educação permanente (FERNANDES, 2007).

A consolidação dos direitos dos usuários da assistência social depende também do esforço de construção de uma política que possa ser expressa, manifestada e deliberada no âmbito da municipalização, pois é no município que a população demandatária se localiza. Por isso, as propostas e sugestões de educação permanente emergentes do âmbito local deverão ser sempre bem-vindas e dignas de reflexões aprofundadas. A consideração desse recorte geográfico é importante, entretanto, é necessário ater-se ao perigo do engessamento da ação profissional que é essencialmente reflexiva.

Essa compreensão contribui também para exaurir as influências do aprisionamento conceitual de que a qualificação continuada advém somente de um único caminho, isto é, do órgão gestor da assistência social, ou das entidades organizativas da categoria, ou, ainda, das instituições formais de ensino. Com isso não se quer afirmar que não há reconhecimento das instituições de ensino em particular, ou, ainda, questionar sua excelência no desempenho da precípua e insubstituível função que possuem na sociedade, mesmo porque temas estruturais referentes à formação e posteriormente continuada, saem das agendas acadêmicas.

Acredita-se não existir antinomias na afirmação de que a qualificação continuada pode ser oportunizada tanto pela via formal quanto pela via informal, pelo contrário, em tempos de deslocamento das ações socioassistenciais para o âmbito do município, conforme preconiza o SUAS, defende-se as consequências positivas e exponenciais que podem ser resultantes da complementação das vias formais e 
informais de educação permanente, tendo como agentes propagadores os próprios profissionais, o órgão gestor da assistência, as entidades organizativas e os programas de pós-graduação.

O que se defende também é que é possível pensar formas alternativas de educação permanente para os profissionais de Serviço Social que atuam no SUAS e que não tem interesse em trilhar pelos caminhos do stricto ou lato sensu, ou ainda, que se encontram impossibilitados de qualificar-se por essas vias. E isso por várias razões, dentre elas questões de ordem financeira, pessoal, impossibilidade de conciliação da jornada de trabalho com o tempo disponível para atividades de educação permanente, enfim. Nessas situações, a busca de aperfeiçoamento por meio do aproveitamento do próprio ambiente de trabalho para realização de reflexões críticas, grupos de estudo dentre outros, a participação em oficinas, workshops, cursos de curta duração, seminários e palestras, ao lado da participação nas ações desenvolvidas pelas entidades organizativas e representativas da categoria profissional igualmente tem sua parcela de importância como contributo para alcance do aprimoramento profissional.

Os ecos das ações do SUAS se refratam nos municípios, mais precisamente nas propostas de intervenções dos profissionais envolvidos com essa política pública, por isso considera-se muito elucidativa a contribuição de Sposati (2006, p. 104) nesse sentido ao prelecionar que: "Os recursos humanos na gestão da assistência social é matéria-prima e processo de trabalho fundamental. A assistência social não opera por tecnologias substitutivas do trabalho humano. Quando usa de tecnologia ela é soft, apoio e não hard, estruturadora." Diante dessa assertiva incontestável, o que dizer da importância da educação permanente desses profissionais?

Seguramente, o processo de qualificação continuada viabiliza a execução de atribuições e competências por parte dos assistentes sociais, no sentido de aprimorar as contribuições que podem oferecer na efetivação de um Sistema que tem muito a percorrer para a consolidação daquilo que está previsto na Constituição Federal de 1988.

\section{Desafios}

Falar em desafios significa assentar-se na ideia de que para essa temática existem diversas vertentes reflexivas que não cabe aqui esgotá-las, nem mesmo se configura como pretensão. Portanto, ao se medir a extensão do assunto, limitar-se-á a 
examinar alguns deles. Além disso, a convivência com desafios por si só é instigante, pois não permite a acomodação no plano teórico e na dimensão prática.

Desafios são realidades dinâmicas que contém o princípio da incerteza que se apresenta como um potencializador e uma mola propulsora para a transformação. Tristão et al. (2009) explicam que "em seu desenvolvimento histórico, as potencialidades humanas emergem por meio de oportunidades que reivindicam sistemas de mediações mais complexas, os quais se apresentam como impulsores e, ao mesmo tempo, resultantes de outros tipos de necessidades humanas" (Ibid., p. 268). Para esses autores:

$\mathrm{O}$ homem tem necessidades físicas elementares, naturalmente determinadas, e precisa produzir os seus meios de vida. Porém suas ações não ficam estagnadas na mera reprodução biológica. Muito pelo contrário, suas carências, suas necessidades de respostas às condições objetivas da vida material e espiritual tencionam avanços que potencializam o desenvolvimento da atividade sensível prática do homem em graus cada vez mais elaborados (TRISTÃO et al., 2009, p. 268).

O desafio pauta-se pelo diálogo entre a dimensão teórico-metodológica e a técnico-operativa do Serviço Social, de forma que se possam vencer as barreiras impostas pela realidade. Os desafios potencializam espaços e oportunidades para o desenvolvimento profissional e impulsionam a busca incessante pela educação permanente. Por essa razão são sua essência.

No contexto contemporâneo, há crescente complexidade decorrente das formas assumidas pelo Estado e sua relação com a sociedade, fato que impõe novos desafios, principalmente, para os profissionais que atuam com a questão social. Esse dinamismo da realidade concreta na qual a profissão se insere possibilita o surgimento dos desafios, os quais significam alternativas de construção do novo, pois permitem que o assistente social possa tornar-se sujeito de sua trajetória profissional pessoal e coletiva.

Cabe ressaltar que educação permanente é processo de longo prazo, materializando-se no decorrer da vida profissional por período indeterminado. Diante disso, e longe da pretensão reducionista em oferecer receitas prontas para diagnósticos evidentes, o que se pretende com a apresentação das narrativas a seguir é corroborar a posição dos entrevistados, situados num tempo e espaço delimitado.

Penso que com o novo reordenamento da Política de Assistência Social no país, os municípios através de seus gestores, terão de cumprir o que preconiza o SUAS, a NOB-RH/SUAS e a Tipificação dos Serviços. Eu acredito que este novo contexto, conquistado por 
muitos anos de lutas desde a Lei Orgânica da Assistência Social, poderá possibilitar mudanças na maneira de pensar, repensar e entender as políticas da área da assistência social por parte dos gestores e, quem sabe, de dirigentes das organizações sociais. Eu desejo e espero que as mudanças sejam de acordo com o que determina a Política Nacional da Assistência Social, e que nossa categoria possa ser mais valorizada e respeitada independentemente dos vínculos trabalhistas. (E1)

Bom, eu penso que o que sabemos e como atuamos, depende da nossa própria vontade em nos atualizarmos quanto à metodologia, questões técnicas, legislações e procura por literatura apropriada. Eu espero que esta narrativa somada às demais, possam ter voz no sentido de alteração da situação referente à formação continuada, bem como despertar nos gestores municipais a sensibilidade para que de fato e de direito apoiem a equipe da base. Espero também que as informações possam chegar formalizadas, que nós um dia possamos ser mais respeitados em nossas potencialidades e que sejamos reconhecidos como transformadores da realidade social. (E5)

O conteúdo presente nas narrativas demonstra o quanto os desafios se fazem presentes numa intervenção profissional voltada à implementação de uma política com potencial emancipatório. E, apesar dos históricos intentos da Política de Assistência Social estarem permeados pela restrição, reforçando seu caráter paliativo e seus propósitos limitados a dissolução de problemas e situações de acirrada privação, também denominadas situações de risco e vulnerabilidade social, o potencial emancipatório dessa política se faz presente. E esse potencial é evidente e é de se esperar numa política pública, que afirma assumir a responsabilidade pela garantia de acesso aos direitos (PAIVA, 2006).

Os assistentes sociais entrevistados chamam a atenção também para o fato da não efetivação da NOB-RH/SUAS, na medida em que os interesses presentes no cenário da assistência social são capturados pelo poder hegemônico. Esses profissionais, ao se submeterem à lógica de uma atuação clivada por essas contradições, em certa medida, imprimem em suas respectivas ações um caráter incompatível com aquilo que é defendido no SUAS. Isso se verifica com maior intensidade no contexto das organizações sociais, embora as falas apresentadas sejam unânimes no que diz respeito à não efetivação da NOB-RH/SUAS em toda sua dimensão.

Identifica-se também nas narrativas que a efetivação da Resolução no 109, de 25 de novembro de 2009, acerca da Tipificação Nacional de Serviços Socioassistenciais não encontra eco consentâneo na realidade cotidiana do profissional. A Tipificação Serv. Soc. \& Saúde, Campinas, SP v. 13, n. 2 (18) p. 299-322 jul./dez. 2014 ISSN 1676-6806 
Nacional dos Serviços Socioassistenciais em diversas passagens defende que a integralidade do atendimento às necessidades das famílias favorece o acesso à garantia de seus direitos, o que se efetiva justamente por meio da articulação em rede (BRASIL, 2009).

Ao destacar a articulação em rede, necessária ao Serviço, a Tipificação reconhece que um dos principais desafios das políticas públicas é superar a fragmentação das e nas políticas públicas. Tal superação possibilita uma visão integrada dos problemas sociais e de suas soluções, exigindo, por sua vez, uma alteração na forma de comunicação e ação dos diversos segmentos da organização governamental e dos seus interesses (BRASIL, 2012, p. 65).

Pode-se afirmar, então, que a articulação em rede tão necessária e proposta na referida Resolução no 109 não se concretiza segundo o previsto. Isso remete ao entendimento de que alguns dos legados da prática assistencial tradicional se constituem em desafios de composição variada, desde os mais simples e comuns aos mais complexos, que se situam na base das intervenções e dos pensamentos dos profissionais. E ainda outros que se fazem presentes no cotidiano do assistente social, representados por desafios de várias ordens e de distintas dimensões proeminentes do próprio processo de implementação e consolidação do SUAS.

Assim, longe da hipervalorização da atuação do profissional de Serviço Social dentro da Política de Assistência Social, fazendo dessa atuação uma panaceia, acreditase que os desafios que se apresentam no dia a dia movem o profissional na direção de uma contínua superação de sua prática, superação que se efetiva, dentre outros aspectos, pela mediação da educação permanente.

Considera-se também que a produção de novas ou modificadas formas de intervenção é consequência do movimento que se faz no intuito de superar os desafios, tendo ou não como meta e como propósito profissional a educação permanente. Com isso, não se está contradizendo a importância da educação permanente na trajetória profissional, como aquela que guarnece a atuação do assistente social, conferindo maior centralidade no âmbito da eficácia e da eficiência, ampliando conhecimentos à atuação, mas reforça-se o aspecto positivo contido também nos desafios que, à primeira vista, podem aparentar estar envolvidos somente por um invólucro negativo. Isso ocorre porque o caráter de potencialidade existente nos desafios não é passível de ser valorado quando se considera apenas sua aparência, é preciso buscar na sua essência os aspectos potencializadores que possui. 
Os desafios se apresentam como possibilidades abertas, mesmo quando situados numa dimensão interventiva repleta de contradições, como demonstra também as narrativas dos entrevistados ao afirmarem que, não obstante as limitações e as dificuldades, buscam a educação permanente de forma autônoma no desejo de superar os desafios que emergem da intervenção, evitando com isso uma leitura retilínea da ação profissional pautada pelo senso comum.

O SUAS desafia todos os agentes envolvidos na sua operacionalização a voltarem-se para a legitimação do caráter público que essa política assume na atualidade. Portanto, negar o conservadorismo, bem como superar a lógica da acomodação de conflitos, historicamente presente nas práticas profissionais e na sociedade como um todo, significa estar diante de um contínuo e grande desafio, haja vista a tradição que demarcou e imprimiu na assistência uma característica interventiva mistificada de cunho simplesmente adjutório, marcadamente compensatório e parcial nas respostas emitidas para diminuição da pobreza, e que encobriu suas ações e medidas de insuficientes aparatos financeiros, humanos e materiais (PAIVA, 2006).

A assistência social, na medida em que procura fazer valer nos espaços sociopolíticos e sócio ocupacionais sua lógica pautada na hegemonia de um projeto político novo, conforme preconiza o SUAS, requer a disseminação crescente do reconhecimento da importância da educação permanente para os profissionais envolvidos na busca pela qualidade dos serviços prestados (PAIVA 2006).

Dadas às novas dimensões que implicam a consolidação do SUAS em todo o território nacional, o reconhecimento da relativa autonomia do assistente social e da presença das dimensões éticas e técnicas que os instiga a buscar o novo e a ousar na formulação de estratégias interventivas, é considerado por esses profissionais como condição para o avanço da Política da Assistência (SILVEIRA, 2009).

Entretanto, essa constatação não se verifica com tanta veemência quando se parte do ponto de vista dos órgãos gestores da Assistência Social, porque, conforme se evidenciou anteriormente nas falas dos assistentes sociais entrevistados 1 e 5 , em especial na narrativa que segue do entrevistado 2, o reconhecimento do alcance das ações desses profissionais, a valorização de sua intervenção bem como, a importância da educação permanente tem sido ainda um tanto negligenciada:

Seria de grande valia que os órgãos das três esferas estatais refletissem sobre este tipo de investimento, que impactaria no resultado que tanto 
prometem em suas campanhas políticas: a melhor qualidade de vida dos usuários da Assistência. (E2)

Portanto, está em aberto o desafio de construir caminhos inovadores que possam subsidiar a consolidação do SUAS e o fortalecimento dos processos de Educação Permanente dos assistentes sociais que atuam no interior da Política da Assistência Social.

\section{Considerações Finais}

A busca reflexiva em torno das propostas e desafios que se colocam quando o que se está em pauta é um repensar da educação permanente do assistente social contribui para que novos horizontes sejam abertos.

Os trabalhadores que atuam na Assistência Social são chamados a envolver-se com a educação social, com a educação para a cidadania. Por isso, a escuta dos assistentes sociais se apresenta como proposta tão importante. E, embora se considere importante afirmar que, no exercício da profissão, o assistente social detém autonomia relativa, dada sua condição de trabalhador assalariado, razão pela qual está sujeito aos imperativos institucionais, o processo que envolve a ação educativa deve ser valorizado, pois permite que o profissional possa sentir-se partícipe da formação continuada e não mero receptivo. Isso reforça a necessidade de se propor continuamente espaços reflexivos em torno da importância da educação permanente, bem como possibilidades de efetivação concreta de um processo continuado de qualificação profissional.

$\mathrm{O}$ alcance da autonomia profissional exige segurança no trato das questões teórico-metodológicas e prático-operativas. Essa segurança se adquire gradativamente, também por meio da educação permanente. Acrescenta-se a ela, o detalhamento da aplicação e da materialidade do conteúdo dessa educação permanente nos municípios e espaços sócio ocupacionais. Aquilo que é demandante em termos de educação permanente em cada período histórico da assistência social também precisa ser considerado, por exemplo, temas contemporâneos situados no universo teóricometodológico e técnico-operativo da profissão e da própria PNAS.

Compreende-se que o avanço na prática ocorre quando se coloca numa disposição de permanente escuta, pois o reconhecimento dos limites permite encontrar possibilidades. E mesmo quando se depara com limitações teórico-metodológicas e prático-operativas, o fato de descobrir o interesse do profissional em querer se envolver Serv. Soc. \& Saúde, Campinas, SP v. 13, n. 2 (18) p. 299-322 jul./dez. 2014 ISSN 1676-6806 
com processos contínuos de educação permanente já evidencia a presença de uma postura receptiva às novas formas de repensar seu fazer profissional.

O estrato da formação continuada alcança-se mais facilmente após análise da realidade, assumindo uma postura reflexiva a partir de dentro e não de fora das necessidades que se têm, por isso a importância de se escutar os profissionais dos diversos municípios por meio do mapeamento das necessidades dos entrevistados, o que permitiu a emersão de propostas e desafios.

Partindo da vivência profissional cotidiana e da percepção que os assistentes sociais têm de educação permanente, independente dessa percepção se apresentar como limitadora ou possibilitadora de desenvolvimento, é possível pensar estratégias de educação permanente voltadas ao aprimoramento profissional. Por fim, considera-se que os desafios podem favorecer a capacidade superlativa dos assistentes sociais para se voltarem com maior intensidade à dimensão teórico-metodológica e técnico-operativa da profissão. Da mesma forma, tais desafios, quando assumidos como um convite a caminhar sempre na direção da qualidade dos serviços prestados e na perspectiva do aprimoramento profissional, possibilitam que se minimizem os efeitos de uma prática reiterativa pautada na simples adequação às rotinas e procedimentos e desprovida de uma análise crítica, assumindo uma dimensão ético-política.

\section{Referências bibliográficas}

BRASIL. Ministério do Desenvolvimento Social e Combate à Fome. Secretaria Nacional de Assistência Social. Política Nacional de Assistência Social. Brasília, DF, 2004.

BRASIL. Ministério do Desenvolvimento Social e Combate à Fome. Secretaria Nacional de Assistência Social. Norma Operacional Básica de Recursos Humanos do SUAS. Brasília, DF, 2007.

BRASIL. Diário Oficial da República Federativa do Brasil, 25 nov. 2009. Resolução no 109, de 11 de novembro de 2009. Dispõe sobre a Tipificação Nacional de Serviços Socioassistenciais, Brasília, DF, 2009.

BRASIL. Ministério do Desenvolvimento Social e Combate à Fome. Secretaria Nacional de Assistência Social. Orientações Técnicas sobre o PAIF:O Serviço de Proteção e Atendimento Integral à Família - PAIF, segundo a Tipificação Nacional de Serviços Socioassistenciais. Brasília, DF, 2012. 
CARVAlHO, M. C. B. de. Assistência Social: reflexões sobre a política e sua regulação. Revista Serviço Social \& Sociedade. São Paulo, v. 27, n. 87 Especial, p. 123-131, set. 2006. 209 p.

CONSELHO FEDERAL DE SERVIÇO SOCIAL (Org.). A Atuação do Assistente Social no CRAS. Cadernos, v. 4. São Paulo: Publicação do CRESS-SP 9a Região, 2009. (Sistematização de dados do levantamento realizado pela Comissão de Orientação e Fiscalização COFI-CRESS-SP 2009). 86 p.

CONSElHO FEDERAL DE SERVIÇO SOCIAL. (Org.) Política de Educação Permanente do Conjunto CFESS-CRESS. Brasília: [s.n.], 2012. Disponível em: <www.cfess.org.br>. Acesso em: 20 set. 2012.

CONSElHO REGIONAL DE SERVIÇO SOCIAL. Código de Ética do Assistente Social. 3. ed. Brasília: Teixeira Gráfica e Editora, 2007. 52 p.

DINIZ, T. M. R. G. O Estudo de Caso. In: MARTINELLI, M. L. Pesquisa Qualitativa: um instigante desafio. São Paulo: Veras, 2003. p. 41-58. 143 p.

FERNANDES, R. M. C. Educação Permanente: um desafio para o Serviço Social. Textos \& Contextos. Porto Alegre, v. 6, n. 1, p. 207-218, jan./jun. 2007. 218 p.

GATti, B. A. (Coord.); BARRETO, E. S. de S. Professores do Brasil: impasses e desafios. Brasília: UNESCO, 2009. 294 p.

GUERRA, Y. O potencial do ensino teórico-prático no novo currículo: elementos para o debate. Katálysis. Florianópolis: EDUFSC, v.8, n. 2, p.147-154, jul./dez. 2005. 268 p.

IAMAMOTO, M. V. Serviço Social: contribuições analíticas sobre o exercício profissional. Katálysis. Florianópolis: EDUFSC, v.8, n. 2, p.139-142, jul./dez. 2005. $268 \mathrm{p}$.

LOPES, M. H. C. O tempo do SUAS. Serviço Social \& Sociedade. São Paulo, v. 27, n. 87 Especial, p. 76-95, set. 2006. 209 p.

MOTA, A. E. et al. O Sistema Único de Assistência Social e a Formação Profissional. Serviço Social \& Sociedade. São Paulo, v. 27, n. 87, Especial, p. 163-177, set. 2006. 209 p.

NOGUEIRA, V. M. R. Intervenção Profissional: legitimidades em debate. Katálysis. Florianópolis: EDUFSC, v. 8, n. 2, p.185-192, jul./dez. 2005. 268 p. ISSN 1982-0259.

PAIVA, B. A. de. O SUAS e os direitos socioassistenciais: a universalização da seguridade social em debate. Serviço Social \& Sociedade. São Paulo, v. 27, n. 87 Especial, p. 5-24, set. 2006. 209 p. 
RAICHELIS, R. Intervenção profissional do assistente social e as condições de trabalho no SUAS. Serviço Social \& Sociedade. São Paulo, v. 31, n. 104, p. 750-772, out./dez. 2010. 793 p.

SILVEIRA, J. I. Sistema Único de Assistência Social: institucionalidade e processos interventivos. Serviço Social \& Sociedade. São Paulo, v. 30, n. 98, p. 335-361, abr./jun. 2009.400 p.

SPOSATI, A. O primeiro ano do Sistema Único de Assistência Social. Serviço Social \& Sociedade, São Paulo, v. 27, n. 87, Especial, p. 96-122, set. 2006. 209 p. SPOSATI, A. Pesquisa e produção de conhecimento no campo do Serviço Social. Katálysis. Florianópolis: EDUFSC, v.10, n. especial, p.15-25, 2007. 96 p.

TRISTÃO. E. L. et al. O processo de mundialização do capital e sua forma "adequada" de conhecimento. Serviço Social \& Sociedade. São Paulo, v. 30, n. 98, p. 245-282, abr./jun. 2009. 400 p. 